\title{
Bronchopulmonary Dysplasia
}

National Cancer Institute

\section{Source}

National Cancer Institute. Bronchopulmonary Dysplasia. NCI Thesaurus. Code C90599.

Chronic lung disease requiring treatment with oxygen for at least 28 days and with a spectrum of severity from mild to severe, that predominantly affects premature infants. While the radiologic pattern is typical in the closer to term patient, the pattern in the small preterm infant is very non-discrete and variable. 